\title{
O valor dos estudos iconográficos para o
} conhecimento arqueológico: a identificação de um código pictórico compartilhado por sociedades do sudoeste dos EUA e da Mesoamérica

The value of the iconographic studies for the building of archaeological knowledge: the identification of a pictorial code shared by the Southwest and Mesoamerica

DOI: 10.20396/rhac.vil.13626

CÁSSIA BARS HERING

Doutora pelo Museu de Arqueologia e Etnologia da Universidade de São Paulo (MAE/USP)

(D) 0000-0003-3014-8375

\section{Resumo}

Os padrões arqueológicos Anasazi, Mogollon e Casas Crandes floresceram na atual região sudoeste dos EUA entre aproximadamente 500 d.C. e 1500 d.C. Por meio de pesquisas realizadas entre 2010 e 2015, voltadas principalmente à análise da iconografia expressa em suportes cerâmicos, foi verificada a existência de um "código pictórico" em comum, compartilhado pelos diferentes grupos humanos associados a estes padrões. Sendo que foi constatado que este "código" foi amplamente expresso ao longo de extensos territórios, e também mantido por um longo período, foi considerado oportuno verificar também a ocorrência de alguns de seus "símbolos principais" na iconografia produzida em épocas concomitantes por grupos de regiões vizinhas, tais como as áreas norte e central da Mesoamérica.

Palavras-chave: Código pictórico. Arqueologia cognitiva. Cosmografia.

\begin{abstract}
The archaeological patterns know as Anasazi, Mogollon and Casas Crandes flourished in the Southwest region of the U.S. between A.D. 500 and 1500. Archaeological and iconographic researches conducted from 2010 to 2015 were able to demonstrate that these archaeological patterns shared a common "pictorial code", broadly observed in their ceramic production found through a vast territory, covering a substantial time lapse. Considering that this "pictorial code" was present and verified through such extensive areas, its existence was also investigated in the material production of the surroundings areas of north and central Mesoamerica.
\end{abstract}

Keywords: Pictorial code. Cognitive archaeology. Cosmography. 
Análises da iconografia expressa em suportes cerâmicos, relativa a padrões arqueológicos ${ }^{1}$ da Região Sudoeste dos EUA, constataram a existência de um "código pictórico" em comum. Tal "código" seria compartilhado pelos diferentes grupos humanos associados a estes padrões [vide Figura 1 e 2]. A produção e reprodução desse "código" permanece de certo modo viva desde períodos formativos até hoje $^{2}$. É possível constatar sua presença nos artefatos etnográficos produzidos pelas sociedades indígenas atuais do Sudoeste, herdeiras dessas antigas tradições. Muitos dos símbolos que compõe esse "código pictórico do Sudoeste", entretanto, podem ser também encontrados na iconografia mesoamericana, demonstrando sua ampla recorrência ao longo de impressionantes lapsos temporais e extensões territoriais.

Para a realização destes estudos, foi eleito um corpo documental de 1451 peças ${ }^{3}$, relativas aos padrões arqueológicos Anasazi, Mogollon e Casas Grandes. A fim de verificar a possível permanência deste "código pictórico" em artefatos etnográficos desta mesma região, foram analisados também 230 peças com essas características ${ }^{4}$ Já para a investigação da presença de símbolos compartilhados na iconografia mesoamericana, foram analisados 191 artefatos. As peças analisadas, em sua grande maioria, pertencem aos acervos do Smithsonian National Museum of Natural History (NMNH) e ao American Museum of National History $(\mathrm{AMNH})^{5}$.

Pode-se dizer que os recipientes cerâmicos arqueológicos aqui analisados eram, de modo geral, utilizados durante seu "ciclo de vida" para cumprir diferentes funções (como servir alimentos, estocar bens de consumo, portar oferendas, ou servir como itens de comércio ou de prestígio) ${ }^{6}$. Tais artefatos, de qualquer forma, carregavam uma carga simbólica significativa, representante das crenças de grupos

\footnotetext{
' Utiliza-se aqui o termo "padrão arqueológico" - cunhado por Lekson como modo de fazer referência às manifestações destes grupos pretéritos, sem que a elas fossem automaticamente associadas etnias específicas. LEKSON, S. H. A History of the Ancient Southwest. Santa Fe: SAR Press, 2010.

${ }^{2}$ Os períodos formativos datam de aprox. 500 d.C.

${ }^{3}$ Sendo: 642 - Anasazi; 402 - Mogollon, e 407 - Casas Grandes

${ }^{4}$ Os artefatos etnográficos, diferentemente dos arqueológicos, apresentam iconografia expressa em suportes materiais variados, tais como cerâmica, tecido, cestaria etc. São provenientes de diversas etnias e grupos atuais, com destaque para os grupos Pueblo Hopi e Zuni.

${ }^{5}$ Para complementar o estudo das peças arqueológicas relativas às esferas da Região Sudoeste foram também utilizados acervos de outros museus, tais como o Logan Museum of Anthropology (LMA); Peabody Museum (PM); Centennial Museum and Cardens (CMG); Maxwell Museum of Anthropology (MMA); Metropolitan Museum of Art; The Anasazi Heritage Center (AHC); Chapin Mesa (CMM); Edge of the Cedars State Park (ECSPM); Salmon Ruins (SEM) e Aztec Ruins (ARM). A base de dados de objetos etnográficos consultada foi a estabelecida pelo AMNH. Para a análise de artefatos pertencentes ao contexto mesoamericano, foi utilizada também a base de dados do AMNH e do NMNH, além do St. Louis Art Museum (SLAM) e do Museo Regional Michoacano (MRM). Os artefatos mesoamericanos arqueológicos analisados apresentam iconografia expressa em suportes materiais variados (tais como cerâmica, líticos, ósseos, malacológicos etc.).

${ }^{6}$ Uma exceção seriam os recipientes cerâmicos escultóricos, cuja maioria não apresentava marcas de uso. Tal fato pode também ser devido a seu formato pouco funcional, sendo estes ligados principalmente a esfera ritual.
} 
humanos unidos por uma "visão de mundo" muito similar. A cosmovisão destes grupos não via distinção entre a vida cotidiana e ritual; entre o utilitário e o sagrado. Ela permeava todas as ações.

As cerâmicas do Sudoeste são divididas pelos especialistas em incontáveis tradições e fases. Como comenta Riley ${ }^{7}$

para propósitos classificatórios os especialistas têm geralmente se concentrado nas diferenças das cerâmicas, estabelecendo tradições separadas (...) mas eu tenho notado também semel hanças incríveis, na complexidade do layout, nos elementos de design, na exuberância geral e em "assuntos" dos estilos, os quais formam um tipo de "macro tradição" (...) algo disso é devido à grande extensão de divulgação, mais ou menos independente, de estilos cerâmicos em várias partes do Sudoeste.

Deste modo, foi proposto um olhar para o corpo documental aqui eleito que buscou não enfatizar as diferenças propostas pelas tradicionais classificações de "fases e/ ou "tradições", mas sim as semelhanças em termos de temática e mensagem (ou "assunto", como aponta Riley, acima) observadas na iconografia dessas cerâmicas ${ }^{8}$. A análise dessa "temática" proporcionou uma melhor compreensão sobre o grau de extensão e características deste "código pictórico".

O trabalho realizado teve como foco tanto análises quantitativas como qualitativas; que se preocuparam tanto com as semelhanças formais dos símbolos analisados, como com as possíveis interpretações a eles atribuída (com base nos conhecimentos advindos da etnografia, arqueologia e etnoarqueologia) ${ }^{9}$. Neste artigo, entretanto, serão demonstrados principalmente os resultados das análises quantitativas, bem como a metodologia utilizada para a identificação dos símbolos que formam este "código pictórico".

\footnotetext{
${ }^{7}$ RILEY, C. L. Becoming Aztlan: Mesoamerican Influences in the Greater Southwest, AD 1200-1500. Salt Lake City: University of Utah Press, 2005, p. 139.

${ }^{8}$ Como dito acima, a diferenciação entre "tradição", "fases", ou outras subdivisões subsequentes, não foi o foco desse trabalho. Entretanto, foi mesmo assim realizada uma verificação nesse sentido, a fim de observar se essas supostas diferenças técnicas se relacionavam ou não com a presença de certos símbolos na iconografia cerâmica. Os resultados mostraram-se, entretanto, infrutíferos. Como lembra Dunnell, "geralmente (...) a maioria das classificações é aceita sem questionamento. Existe pouca ou nenhuma preocupação em estabelecer como e porque essas classes vieram a existir. A classificação costuma ser feita por si só (...) as classes utilizadas devem ser função de um problema para que possam dizer alguma coisa - para que sejam sujeitas a teste e avaliação e aceitas por sua utilidade, e não por uma questão de fé". DUNNELL, R. C. Classificação em Arqueologia. São Paulo: Edusp, 2007, p. 214-215.

9 BARS HERING, C. O Dilema das "Fronteiras" Geográficas e Culturais ao Norte da Mesoamérica. Tese (Doutorado em Arqueologia) - Programa de Pós-Graduação do Museu de Arqueologia e Etnografia, Universidade de São Paulo, São Paulo, 2015.
} 


\section{Procedimentos de análise - Uma Leitura Gestáltica}

Zubrow afirma que há um "conhecimento comum" na arqueologia, que não está sujeito a interpretações pessoais, "ele existe além do indivíduo e além das culturas". ${ }^{10}$ A possibilidade do entendimento dos processos cognitivos da mente humana permitiria a compreensão de diferentes aspectos gerais de classificação e organização, bem como dos "cognitivos universais" ." O pesquisador acredita na existência de algo como uma "gramática pré-histórica", regras gerais que devem ser desvendadas a fim de se compreender "como os seres humanos representam o conhecimento, e o que eles fazem com estas representações". ${ }^{12}$ Existiria, então, um "código universal de significado", ao qual chegaríamos depois de eliminarmos os "filtros" da cultura, espaço e linguagem. Estes "cognitivos universais" seriam os "blocos construtores necessários ao entendimento da cognição, que nos forneceriam uma base para fazer comparações" ${ }^{13}$

Como lembra Renfrew, a análise destes "cognitivos universais", deve também levar em consideração que:

a experiência humana ocorre através do ato de lidar com o mundo material (...) o homem apreende o mundo e age sobre ele não só através de seus corpos, mas também através dos artefatos (...) o fenômeno da mente é em grande parte, coletivo e social (...) a mente, nesse sentido, é um fenômeno compartilhado. ${ }^{14}$

"Mente" e "matéria", portanto, se unem em novos comportamentos simbólicos, e por esse motivo, não devem ser consideradas entidades distintas ${ }^{15}$. Nessa configuração, é possível considerar o "símbolo" ainda como uma outra "entidade" - que teria sua existência inseparável tanto do objeto no qual está representado, como da mente humana. Os símbolos também compõem novos sentidos, e influenciam e

\footnotetext{
${ }^{10}$ ZUBROW, E. B. W. Cognitive Archaeology Reconsidered. In: RENFREW, C.; ZUBROW, E. B. W. The Ancient Mind: Elements of Cognitive Archeology. Cambridge: Cambridge University Press, 1994, p. 187 (a).

${ }^{11}$ Ibidem, p. 187-188. Destaca-se que além de Zubrow, outros pesquisadores como Renfrew e Mithen, também assumem que não há nenhuma distinção entre a mente "antiga" e a "moderna". RENFREW, C. Towards a Cognitive Archaeology. In: RENFREW; ZUBROW, op. cit., p. 3-11; MITHEN, S. The Prehistory of the Mind: The Cognitive Origins of Art, Religion and Science. Cambridge: Cambridge University Press, 1996

${ }^{12}$ ZUBROW, E. B. W. Knowledge Representation and Archaeology: a Cognitive Example Using GIS. In: RENFREW; ZUBROW, op. cit., p. 109 (b).

${ }^{13}$ Ibidem, p. 110

${ }^{14}$ RENFREW, C.; BAHN, P. Archaeology: theories, methods and practice. $5^{\mathrm{a}}$ ed. Londres: Thames \& Hudson LTD, 2008, p. 426. ${ }^{15}$ A "dicotomia" entre mente e matéria tampouco é aceita por autores como: HODDER, l. et al (eds.). Interpreting Archaeology: Finding Meaning in the Past. Londres: Routledge, 1995; TILLEY, C. (ed.). Interpretative Archaeology. Oxford: Berg, 1993; BARRETT, ]. Fragments from Antiquity. An Archaeology of Social Life in Britain (2900-1200 BC). Oxford: Blackwell, 1994; COSDEN, C. Making Sense: Archaeology and Aesthetics. World Archaeology, v. 33, n. 2, 2001, p. 163-167; e THOMAS, J. Time, Culture and Identity. Londres: Routledge, 1996, entre outros.
} 
são influenciados tanto pelo comportamento humano, como pela utilização da matéria suporte. ${ }^{16} \mathrm{Tem}$ se então, "mente, matéria e símbolo" compondo um todo inseparável que pode ser chamado de "fenômeno da mente". ${ }^{17}$ Adiciona-se aqui à denominação de Renfrew, além da "mente humana" e da "matéria", o elemento "símbolo", ao mesmo tempo material, em sua apresentação, e imaterial, em seu sentido. Uma "entidade" que se coloca tanto no "mundo das ideias", como no "mundo da matéria"; quase um elo que possibilita a união "mente e matéria".

Baseando-se então nestes postulados, e na afirmação de Zubrow de que a arqueologia cognitiva deve ser "sinteticamente científica e interpretativa ${ }^{18 "}$ foi proposta a adoção de uma metodologia que busca unir as bases analíticas dos pressupostos teórico-metodológicos da Cestalt ${ }^{19}$ (no campo das análises puramente formai $\mathrm{s}^{20}$ ), e a interpretação dos discursos com base no conhecimento acerca da cosmovisão das populações estudadas, e dos contextos nos quais eram criados estes objetos. Neste artigo, como comentado, será dado enfoque às análises quantitativas formais, de modo a comprovar seu grande valor para os estudos em arqueologia.

Os pressupostos da Gestalt e as abordagens em psicologia evolutiva (que consideram que o cérebro humano opera através de padrões funcionais subordinados a leis gerais), já foram alvo de críticas no campo dos estudos iconográficos. Estas críticas partiram principalmente da antropologia social, que de modo geral, considera que os processos estéticos estariam geralmente ligados ao condicionamento cultural, e talvez algumas sociedades possam não possuir os mesmos condicionamentos. ${ }^{21}$ Entretanto,

\footnotetext{
${ }^{16}$ Nesse sentido, é pertinente expor aqui que Ceertz teria sido um dos primeiros estudiosos a afirmar que os "símbolos transformam o mundo", ou seja, que possuem, portanto, certa capacidade de ação por si sós. Ver: LAGROU, E. M. Antropologia e Arte: uma relação de amor e ódio. Ilha, v. 5, n. 2, dez. 2003, p. 93-113. Mais tarde, Lagrou afirma que "a 'eficácia da arte' reside na capacidade agentiva da forma, das imagens e dos objetos". Ver: LACROU, E. M. Arte ou artefato? Agência e significado nas artes indígenas. Revista Proa, v. 1, n. 2, 2010, p. 13.

${ }^{17}$ Assim como denominou Renfrew em: RENFREW, C. Symbol before Concept - Material Engagement and the Early Development of Society. In: HODDER, I. Archaeological Theory Today. Cambridge: Polity Press, 2001, p. 122-140.

${ }^{18}$ ZUBROW, op. cit., 1994a, p. 107

${ }^{19}$ A Cestalt é uma escola de psicologia experimental cujos principais expoentes foram o filósofo austríaco Christian Von Ehrenfels, Max Wertheimer, Wolfgang Kohler e Kurt Kofka. O movimento gestaltista atuou principalmente no campo da teoria da forma, e se opõe a uma percepção subjetiva, "pois a psicologia da forma se apoia na fisiologia do sistema nervoso, quando procura explicar a relação sujeito-objeto no campo da percepção". COMES FILHO, J. Gestalt do Objeto. Sistema de Leitura Visual da Forma. São Paulo: 2009, p. 18. Lembra-se aqui também que Lagrou afirmou que "quando uma leitura iconográfica de unidades isoladas (dos grafismos) parece confusa e contraditória, é necessário introduzir uma leitura mais gestáltica ou estrutural dos padrões como um todo, o que proporciona (...) uma melhor compreensão dos seus usos e significados. Analogias entre esse código visual e outros códigos verbais e não verbais, que juntos formam o pano de fundo para a significação cognitiva e emocional do estilo artístico e, consequentemente do seu poder agentivo, são essenciais". LAGROU, E. M. A fluidez da forma: arte, alteridade e agência em uma sociedade amazônica. Rio de Janeiro: Topbooks, 2007, p. 150.

20 "A forma pode ser definida como a figura ou a imagem visível do conteúdo. De um modo prático, ela nos informa sobre a natureza e a aparência externa de alguma coisa. Tudo o que se vê possui forma (...) a forma pode se constituir em um único ponto, ou em uma linha, ou em um plano, ou ainda, num volume". COMES FILHO, op. cit. p. 39.

${ }_{21}$ "De uma perspectiva antropológica, concebe-se a experiência estética como aprendida". VIDAL, L.; SILVA, A.L. Antropologia estética: enfoques teóricos e contribuições metodológicas. In: VIDAL, L. (org.). Grafismo Indígena. São Paulo: Edusp, 1992, p. 281.
} 
alguns estudos nesse campo vêm demonstrando uma certa flexibilização quanto a estes ideais, buscando compreender a linha divisória entre o "universal" e o "particular". Lux Vidal e Aracy L. da Silva admitem terem consciência da importância da questão quando se perguntam:

até que ponto esses valores são culturalmente condicionados e até que ponto são algo humanamente universal. De modo geral, para a antropologia, interessa o culturalmente definido sem que, no entanto, descartem-se as possibilidades de investigação a partir de conceitos elaborados pela psicologia, pela teoria da comunicação ou pela estética ${ }^{22}$

Para a realização das análises com enfoque nas questões puramente formais, fez-se necessária a aplicação de uma metodologia que fosse capaz de compreender e identificar tanto o funcionamento dos símbolos em um determinado espaço pictórico, quanto à estruturação da "sintaxe" por eles composta. Segundo ditam os estudos com base na Cestalt, o primeiro passo nesta direção seria a identificação das unidades mínimas de significação, ou seja, do que a semiótica denomina de "sememas", e toma-se aqui dela emprestado este termo. ${ }^{23}$

Os sememas também podem ser chamados de "elementos básicos ${ }^{24 " ; ~ " t r a c ̧ o s " ~ q u e ~ r e p r e s e n t a m ~}$ unidades $^{25}$; unidades primárias ${ }^{26}$; ou "motivos básicos ${ }^{27 "}$. Eles são passíveis de reconhecimento, na medida em que o cérebro do arqueólogo moderno apreende a estruturação das formas no espaço do mesmo modo que os antigos Homo sapiens o faziam ${ }^{28}$. Os olhos apreendem os sememas pois organizam o espaço de "leitura", e induzem ao cérebro a percepção de uma unidade de significação.

Existe uma correspondência entre a ordem que o projetista escolhe para distribuir os elementos de sua composição e os padrões de organização, desenvolvidos pelo sistema nervoso. Estas organizações, originárias da estrutura cerebral são, pois, espontâneas, não arbitrárias, independentes de nossa vontade e de qualquer aprendizado. ${ }^{29}$

\footnotetext{
${ }^{22}$ VIDAL; SILVA, op. cit., p. 280.

${ }^{23}$ OLIVEIRA, A. C. (org.). Semiótica Plástica. São Paulo: Hacker Editores, 2004, p. 116.

${ }^{24}$ LANCDOM, ]. A cultura Siona e a experiência alucinógena. In: VIDAL, op. cit., p. 67-87.

${ }^{25}$ MUNN, N.D. Walbiri iconography: graphic representation and cultural symbolism In a Central Australian society. New York: Cornell Univ. Press, 1973.

${ }^{26}$ PLOG, S. Stylistic variation in prehistoric ceramics: design analysis in the American Southwest. Cambridge: Cambridge University Press, 1980

${ }^{27}$ HENDRICKSON, M. J. Design Analysis of Chihuahuan Polychrome Jars From North American Museum Collections. Tese (Doutorado em Arqueologia) - Faculty of Craduate Studies, University of Calgary, Calgary, 2000

${ }^{28}$ VIALOU, D.; VILHENA VIALOU, A. Art Rupestre, Habitats et Territoires au Brésil. In: El arte prehistórico desde los Inicios del siglo XXI. Primer Symposium Internacional de Arte Prehistórico de Ribadesella, Espanha, 2003, p. 482-511; ZUBROW, op. cit., 1994 b.

${ }^{29}$ FRACCAROLI, C. A percepção da forma e sua relação com o fenômeno artístico: o problema visto através da Gestalt. São Paulo: Edusp, 1952, p. 1.
} 
A escola da Gestalt atribui ao sistema nervoso central, "um dinamismo autorregulador que (...) tende a organizar as formas em todos coerentes (...) a maneira como se estruturam essas formas obedece a uma certa ordem, isto é, essas forças internas de organização se processam mediante relações subordinadas a leis gerais". ${ }^{30}$ Tais "forças internas" foram classificadas pelos estudiosos da Cestalt como princípios de unidade, segregação, unificação, fechamento, continuidade, proximidade, semel hança e pregnância da forma. ${ }^{31}$ Um dos exemplos da validade de aplicação destes princípios pode ser notado nos estudos de Gallois sobre a arte Waiãpi, da região do Amapá. ${ }^{32}$ Apesar de claramente não se basear nos princípios da Gestalt, Gallois afirma que os Waiãpi teriam certos critérios "etnoestéticos" que os fariam considerar mais belas as imagens que teriam firmeza de traço, e que seria muito importante para eles fechar os ângulos dos motivos (obedecendo os princípios de fechamento e continuidade). Além disso, a complexidade na associação de motivos em uma mesma superfície era valorizada, comprovando a validade do princípio de pregnância da forma. ${ }^{33}$ A partir do ponto de vista da Gestalt, portanto, estas "preferências estéticas" dos Waiãpi não estariam ligadas, em certo grau, a critérios "etnoestéticos", ou culturalmente aprendidos. Elas seriam universais.

O cérebro percebe os sememas por meio destes princípios universais, que podem operar simultaneamente. Por exemplo, na Figura 3, notam-se os sememas da "cruz" dispostos no registro da parte superior do bojo do vaso, de coloração mais clara. Eles são facilmente identificados pelo cérebro como unidades de significação, pois há uma "descontinuidade de estimulação", ou seja, um claro contraste com o fundo claro onde estes sememas estão dispostos. ${ }^{34} \mathrm{~A}$ identificação também se dá pelo fato dos sememas estarem a uma certa distância uns dos outros. Este seria o princípio de segregação, que "evidencia [...] ou destaca as unidades [...] dentro de relações formais de posicionamento" ${ }^{35}$

Geralmente, e muito frequentemente, dois ou mais os sememas podem ser unidos para compor novos símbolos visuais únicos, ou sintagmas. ${ }^{36} \mathrm{Após} \mathrm{a} \mathrm{identificação} \mathrm{dos} \mathrm{símbolos} \mathrm{(sejam} \mathrm{eles} \mathrm{sememas} \mathrm{ou}$ sintagmas), deve ser identificada a estruturação, ou "sintaxe", que rege a imagem, ou conjunto de imagens, como um todo. Diferentemente da escrita ocidental convencional, nem sempre as imagens

\footnotetext{
${ }^{30}$ GOMES FILHO, op. cit. p. 20.

${ }^{31}$ Ibidem.

${ }^{32}$ GALLOIS, D. T. Arte iconográfica Waiãpi. In: VIDAL, op. cit., p. 209-230.

${ }^{33} \mathrm{O}$ princípio de fechamento demonstra a necessidade natural de uma ordem espacial que "tende a formação de unidades em todos fechados". Cf.: COMES FILHO, op. cit., p.32. O princípio de continuidade dita que as partes devem se organizar de modo coerente, sem descontinuidades. Já a "pregnância da forma pressupõe que a organização formal do objeto, no sentido psicológico, tenderá a ser sempre a melhor possível do ponto de vista estrutural”. Ibid., p. 37.

${ }^{34}$ A percepção do "fundo" é fundamental para a percepção da unidade, pois "não podemos perceber unidades visuais isoladas, mas sim, relações: um ponto na dependência de outro ponto". Ibid., p. 20.

35 Ibid., p. 30

${ }^{36}$ A palavra "sintagma" compreende em sua essência uma noção utilizada para se referir a qualquer segmento linguístico, como a palavra, a sentença ou o período.
} 
apresentarão uma estruturação clara e articulada do espaço-suporte. Entretanto, tal fato não impede a identificação das relações "semânticas" entre as formas. Muitas vezes não se reconhece o discurso em si, mas é possível reconhecer a "sintaxe". "A intenção semântica de um símbolo dentro de uma composição somente pode ser identificada em associação com outros motivos ${ }^{37 "}$. No mesmo vaso da Figura 3, por exemplo, nota-se que os símbolos do "quadrado com ponto no meio" estão unidos e estruturados intencionalmente dentro de um outro semema, o do "retângulo". Já os símbolos da "cruz" formam, no registro superior, outra estrutura de comunicação. Segundo a Gestalt, o cérebro apreende estas diferentes estruturas semânticas por meio de princípios como o da unificação, proximidade e o da semelhança. ${ }^{38}$

Estas estruturas se dispõem sobre o espaço pictórico que lhe serve de suporte, que por sua vez também deve ser levado em consideração. Seu formato específico, como o bojo arredondado de um vaso por exemplo, também influi na disposição da "mensagem" e em seus modos de "leitura". Há também a questão da escolha do tipo de artefato que serviria como suporte e sua relação com o conteúdo simbólico da mensagem a ser transmitida pela iconografia. Além disso, a inserção social do vaso nas atividades da(s) comunidade(s) a qual pertenceu, além do "público-alvo" para qual a mensagem estaria dirigida, devem ser considerados, sempre que estas informações forem disponíveis.

Abaixo são apresentados os passos seguidos pela metodologia de trabalho assumida nesta pesquisa, tendo em vista às questões puramente formais da iconografia analisada:

1. Separação e identificação dos sememas e dos sintagmas formados por eles, com base na teoria da Gestalt, expostos na iconografia dos artefatos relativos a cada um dos padrões arqueológicos do Sudoeste, analisados a princípio separadamente.

2. Consideração das possíveis estruturas de comunicação formadas por estes símbolos ("sintaxe"), e as relações entre eles.

3. Realização de uma contagem do número de vezes das quais tais símbolos, ou sintaxes semelhantes, apareceram expressas no(s) artefato(s) analisado(s), a fim de verificar sua relevância.

4. Verificação da repetição de sememas, sintagmas e/ou sintaxes em artefatos pertences aos três padrões arqueológicos do Sudoeste eleitos para análise em conjunto.

\footnotetext{
${ }^{37}$ MTHEN, op. cit., p. 255-256.

38 "A unificação da forma consiste na igualdade ou semelhança dos estímulos produzidos pelo campo visual, e sobretudo, a coerência do estilo formal das partes ou do todo". O princípio de proximidade dita que "elementos ópticos, próximos uns aos outros, tendem a ser vistos juntos, e por conseguinte, a constituírem um todo ou parte do todo", já a semelhança dita que "os estímulos mais semelhantes entre si, seja por forma, cor, tamanho, peso, direção e localização, terão maior tendência a ser agrupados, a constituírem partes ou unidades". GOMES FILHO, op. cit., p. 31; 34-35.
} 
5. Verificação da repetição de sememas, sintagmas e/ou sintaxes em artefatos pertences às coleções etnográficas da região Sudoeste eleitas para este estudo.

6. Em adição, verificação da repetição de sememas, sintagmas e/ou sintaxes em um conjunto de artefatos pertences às áreas norte e central mesoamericanas.

Nas Figuras 4 a 8 é possível observar alguns exemplos gráficos relativos aos símbolos analisados neste corpo documental.

\section{Os resultados quantitativos - Análise das Peças Arqueológicas da Região Sudoeste}

Pode-se dizer que as análises quantitativas tornaram possível verificar a relevância de cada um desses símbolos que compõe o código pictórico como um todo, em relação às épocas, locais e/ou às morfologias específicas dos recipientes. ${ }^{39}$ Também por meio dessas análises foi possível prover um panorama claro sobre as articulações semânticas (tais como sintagmas ou sintaxes) providas pelas inúmeras combinações de cada semema em específico.

É de grande relevância notar que todos os sememas identificados foram encontrados nas representações gráficas dos três padrões arqueológicos do Sudoeste analisados, formando sintaxes relevantes semelhantes, e compartilhando também de formações idênticas para muitos sintagmas. É também possível dizer que a grande maior parte dos símbolos que compõe o "código pictórico" identificados ocorreram desde épocas formativas, demonstrando uma continuidade formal muito relevante. ${ }^{40}$

Também considerando os três padrões arqueológicos separadamente, é muito importante citar que, na maioria dos casos, os mesmos símbolos ou sememas tiveram relevância quantitativa semelhante. Por exemplo, os sememas da "voluta", do "escalonado", do "triângulo", e símbolos "quadripartites" são os que mais foram representados, mostrando serem de grande importância para os três padrões arqueológicos. Já o restante dos símbolos identificado foi observado mais ou menos nas mesmas proporções, e se mostrou, em todos os casos, menos relevante..$^{41}$

O estudo das inúmeras possíveis combinações dos mesmos sememas demonstrou que diversos sintagmas são idênticos para os três padrões arqueológicos, e que também algumas combinações

\footnotetext{
39 Nesse presente artigo, será dada ênfase à formação e a identificação do código pictórico em si. Para maiores detalhes sobre outros aspectos dessa pesquisa, como a questão da relação da morfologia dos objetos com os símbolos gráficos, vide BARS HERING, op. cit

${ }^{40}$ Cerca de 65\% dos símbolos analisados ocorreram desde épocas formativas. Quanto aos 35\% restantes, estes ocorreram em época imediatamente subsequente, e portanto também bastante remota. Ibidem.

${ }^{41}$ Vide Figura 5 - exemplos de representações dos símbolos identificados por este estudo.
} 
ocorrem de modo particular, dentro de apenas um padrão em específico. Nesse contexto, é possível dizer que novas combinações dos mesmos sememas permitia a elaboração de diferentes composições de acordo com a "mensagem" a ser passada. A disposição destes símbolos no espaço pictórico também pode ser um tanto variável, obedecendo a particularidades locais [Figuras 9 a 11]

É relevante a constatação de que não há, de modo geral, a criação de novos sememas para estes três padrões arqueológicos, como um todo, ao longo do tempo. O que ocorre é uma profusão de novas ou repetidas formas de combinações destes sememas e sintagmas. Neste sentido, é possível fazer paralelos com estudos iconográficos relativos a outras populações americanas, tais como o trabalho de Müller sobre as representações iconográficas Assurini. ${ }^{42}$ Apesar de a autora analisar a expressão plástica de um grupo bastante distante da realidade da região Sudoeste (tanto em termos temporais como espaciais), pode-se dizer que a mesma estruturação de discurso pictórico foi verificada: os Assurini, da mesma forma, possuem um número finito de "unidades mínimas distintivas" gráficas, que poderiam ser combinadas entre si, formando incontáveis novos desenhos, utilizados de acordo com a intenção do artista. Da mesma maneira, também não é verificada, de modo geral, a criação de novas "unidades gráficas", e sim de novas combinações destes padrões já pré-existentes. Pode-se dizer que Müller descreve a formação e utilização de um "código pictórico" (em nossas palavras), que não pode ser considerado uma "escrita" no sentido mais comumente aplicado ao termo, mas que permite combinações de formas gráficas de modo análogo às combinações de letras ou palavras (porém não com sua estrutura de sentido de leitura fixo, e tampouco com seu valor fonético). Nas palavras de Müller sobre o "código pictórico" Assurini: "estes desenhos possuem significado e sua elaboração segue a gramática própria desse sistema de comunicação, obedecendo regras estéticas e morfológicas". ${ }^{43}$

Também Washburn \& Crowe ${ }^{44}$, ao estudarem símbolos expressos sobre os tecidos andinos (cujas inúmeras combinações podem também compor um "código pictórico"), perceberam que esses símbolos eram combinados de acordo com certas regras específicas, e teceram algumas analogias com a questão gramatical. "Pode-se denominar esta técnica de 'estética sintática' - estes elementos específicos e a regra recursiva que permite sua combinação e recombinação para criar novos arranjos". ${ }^{45}$

A existência de "códigos pictóricos", com tais características, parece indicar uma necessidade de comunicação que atua em uma esfera diferenciada, que tramita em um "espaço virtual" entre as artes visuais de cunho naturalista, e o que geralmente é denominado de "escrita", no senso comum ocidental.

\footnotetext{
${ }^{42}$ MÜLLER, R. P. Tayngava, a noção de representação na arte gráfica Assurini do Xingu. In: VIDAL, op. cit., p. 231-248.

${ }^{43}$ Ibidem, p. 231

${ }^{44}$ WASHBURN, D.; CROWE, D. The Symmetry Comes of Age: role of pattern in culture. University of Washington Press, Seattle, 2004

${ }^{45}$ Ibidem, p. 248.
} 
Este código não deve ser tampouco considerado como um indicativo de uma "pré-escrita", mas sim como uma constatação de que existem outras necessidades de comunicação que talvez não sejam atendidas nem por uma "escrita"- que descreve uma narrativa de fatos específicos e histórias lineares, e nem por uma representação artística naturalista. É muito provável que tais necessidades estejam ligadas primordialmente à comunicação de "conceitos fundamentais" da cosmovisão, assim como também

os desenhos Assurini estão associados à cosmologia e às noções fundamentais da visão de mundo deste povo (...) a predominância do sobrenatural na organização do cosmo e na própria reprodução da sociedade correspondem aspectos formais das representações visuais manifestas nos desenhos geométricos (...) Resumindo, os padrões são noções abstratas e sua realização concreta se dá por intermédio dos desenhos na cerâmica, no corpo e nas cuias. ${ }^{46}$

\section{A Permanência do Código Pictórico em Peças Etnográficas}

A fim de verificar a permanência deste "código pictórico" ao longo de um lapso temporal ainda mais amplo, foram analisadas peças etnográficas, como comentado anteriormente. As peças são provenientes de diversas etnias e grupos atuais, com destaque para os Pueblo Hopi e Zuni. Nota-se que estas peças apresentam um estilo de pintura já bastante modificado, influenciado pelo contato com o europeu e com a atual população americana. Entretanto, percebe-se ainda a presença de diversos símbolos que compõe este "código pictórico" [Figuras 9 a 11]. A permanência tanto de sememas, como de sintagmas e sintaxes semelhantes, é de fato bastante relevante, e demonstra a força e a importância da manutenção deste "código pictórico" dentre as populações do Sudoeste ao longo do tempo.

Alguns estudos, como os de Hardin e Mills ${ }^{47}$ focaram sobre as mudanças estilísticas na cerâmica Zuni. Estas mudanças eram ligadas ao arranjo dos símbolos nos recipientes, e não nos símbolos em si. ${ }^{48}$ As autoras notaram que os recipientes menores quebravam mais facilmente, e desta forma eram mais rapidamente refeitos. Já os maiores pareciam ser bem mais antigos, talvez por serem mais resistentes. Nestes vasos maiores, foi notado que eram feitos os "arranjos" mais tradicionais, enquanto nos menores,

\footnotetext{
${ }^{46}$ MÜLLER, op. cit., p. 241. Outros estudos, como os de Lagrou sobre o sistema de grafismos Kaxinawa, também chegaram a conclusões um tanto semelhantes. Ver: LAGROU, op. cit., p.127. Já Demarchi afirma que através dos grafismos Kaxinawa "ocorre uma comunicação sintética que se refere a todos os níveis sociais e cosmológicos simultaneamente (...) comunica porque, indo além da mera representação de um conhecimento sobre o mundo, consegue expressar, através de um código visual, a simultaneidade e as interconexões de diferentes níveis existenciais ou sociais, capacidade esta impossível de ser realizada pelo código verbal, 'pela simples razão de ser impossível verbalizar tudo de uma só vez'". DEMARCHI, A. Armadilhas, Quimeras e Caminhos: Três Abordagens da Arte na Antropologia Contemporânea. Espaço Ameríndio, v. 3, n. 2, 2009. p. 193.

${ }^{47}$ HARDIN, M. A.; MILLS, B. J. The Social and Historical Context of Short-Term Stylistic Replacement: A Zuni Case Study. Journal of Archaeological Method and Theory, v. 7, n. 3, 2000, p. 139-163.

${ }^{48}$ As posições dos símbolos e representações gráficas no espaço pictórico oferecido pelo corpo dos vasos, de modo "simétrico" ou "assimétrico".
} 
que seriam logo substituídos, eram por vezes realizados alguns "novos arranjos", talvez alguns testes ou inovações. A coleção analisada pelas autoras tinha sido formada entre 1879 e 1881 (em coletas de expedições do Smithsonian - base também aqui em estudo). As coletas constantes a partir do final dos oitocentos incentivaram as vendas das cerâmicas. No início, os Zuni preferiam sempre vender as cerâmicas mais novas, e manter as mais velhas, mas com o tempo e novas pressões sofridas pela sociedade, as peças mais antigas também foram vendidas. As autoras creem que estes recipientes mais antigos poderiam servir de base para que estes "arranjos" mais tradicionais fossem depois copiados. Em muitos desses vasos, alguns estudiosos, como Mera, já haviam identificado o que chamaram de "motivos antigos". ${ }^{9}$

A história dos contatos dos descendentes de europeus com os Zuni não é muito diferente da dos outros grupos Pueblo atuais. Como comentado acima, foi notado também por esta presente pesquisa a forte influência europeia/americana na iconografia sobre a cerâmica etnográfica. Entretanto, diferentemente de Hardin \& Mills, este estudo não focou no arranjo dos símbolos no espaço pictórico, mas na reprodução e na identificação dos símbolos em si, e as combinações de sememas. E estes, seja qual forem os novos arranjos, e também os novos elementos de influência europeia inseridos na pintura, se mantiveram presentes. Existe uma força, uma coesão, que faz com que tais símbolos não morram ou deixem de ser representados, mesmo em meio a um contexto que provocou tantas profundas mudanças significativas em diversos graus e âmbitos dos grupos Pueblo. Este fator chama a atenção para a grande importância desses símbolos para estes grupos.

É importante enfatizar que os símbolos que compõe o "código pictórico" aqui identificado para o Sudoeste estão também presentes em outros suportes materiais além da cerâmica, tais como tecidos, cestaria, escudos, ornamentos, decoração de elementos arquitetônicos, ou murais cerimoniais (tanto no contexto arqueológico, como etnográfico). Interpreta-se aqui essa configuração como um "sistema de design difundido", o qual DeBoer estabelece em oposição ao que o autor chama de "sistema de design segregativo". ${ }^{50} \mathrm{O}$ "sistema de design difundido" indicaria que símbolos expostos em um destes meios, (tais como a cerâmica), ocorreriam amplamente também em outros meios (tais como tecidos, cestaria, etc.), independentemente do tamanho, forma, ou função do objeto. "Um sistema de decoração difundida parece envolver a representação ou a evocação de temas ideológicos centrais para a autoimagem de uma comunidade"..$^{51}$

\footnotetext{
${ }^{49}$ MERA, H. P. The "Rain Bird": A Study of Pueblo Design. Memoir, School of American Research, v. 2, Santa Fe, 1937.

${ }^{50}$ DEBOER, W. The Decorative Burden: Design, Medium and Change. In: LONGACRE, W.A. Ceramic Ethnoarchaeology. Santa Fe, N.M.: School of American Research, 1991, p. 144-161.

${ }^{51}$ BRAUN, D. P. Why Decorate a Pot? Midwestern Household Pottery, 200 B.C.-A.D.600. Journal of Anthropological Archaeology n. 10, 1991, p. 366.
} 


\section{A presença dos principais símbolos deste código pictórico também na Mesoamérica}

Sendo o "código pictórico", identificado para o Sudoeste, considerado como uma "cosmografia"52, entendeu-se ser oportuno dar atenção também ao fato de que é possível encontrar muitos destes símbolos representados em artefatos mesoamericanos. Estando estes símbolos não destituídos de significado, eles poderiam também ser importantes indícios de ideias compartilhadas, ou trocadas, entre estas duas grandes áreas.

Apesar de muitos dos símbolos abstratos identificados neste estudo terem fortes similaridades com símbolos também encontrados na Mesoamérica, é muito mais comum que os pesquisadores da área se utilizem da "iconografia naturalista" para traçar importantes conexões entre o Sudoeste e seus vizinhos ao sul. Acredita-se que isso se dá principalmente pela identificação de algumas representações zoomorfas e antropomorfas, que denotam muitas semel hanças com certas representações de divindades mesoamericanas. ${ }^{53}$ Nota-se também que, a despeito da existência de incontáveis estudos focados na compreensão da iconografia mesoamericana em particular, muito poucos destes voltaram-se exclusivamente à tentativa de interpretação dos símbolos abstratos. Muito do que se sabe sobre o teor destes símbolos está ligado a estudos voltados principalmente à interpretação de imagens naturalistas (que acabam por abordar também algumas imagens abstratas ${ }^{54}$ ), ou a estudos que se dedicam às interpretações de "textos", tais como os contidos nos códices.

Dentre os escassos trabalhos voltados exclusivamente a esta questão (e que não imediatamente associam estes símbolos aos de escrita pictoglífica), estão os de Enciso ${ }^{55}$ e Frauel et al. ${ }^{56} \mathrm{O}$ trabalho de Frauel et al. é bastante sistemático, e nesse sentido, semelhante ao realizado por esta presente pesquisa. Os autores também se preocuparam em identificar os símbolos com base na construção e disposição de suas linhas gerais, não permitindo assim que possíveis diferentes estilos de representação interferissem em seu reconhecimento. Nas palavras dos autores, "o trabalho descreve uma técnica para reconhecer

\footnotetext{
${ }^{52}$ Ou um meio de expressão para conceitos fundamentais de suas cosmovisões. BARS HERING, op. cit.

$53 \mathrm{lbidem}$.

${ }^{54}$ Como por exemplo, o trabalho de Quesada Garcia. O foco de seus estudos recai em imagens de "deuses e suas manifestações" mesoamericanas, mas ele também acaba por notar a importância de certos símbolos, ou "elementos gráficos significantes, ou seja, que possuem significados próprios, intrínsecos a sua forma e aparência (...) tem um significado per se". QUESADA CARCÍA, O. Tres signos: escritura antigua de Mesoamérica. México, D.F.: Universidad Nacional Autónoma de México, 2006, p.16. Outro exemplo é o trabalho de Lopez-Austin, o qual aborda a questão específica de um símbolo toponímico, mas que também acaba por abordar a questão dos elementos quadripartites nele presentes. LÓPEZ AUSTIN, A. Ligas Entre el Mito y el Ícono en el Pensamiento Cosmológico Mesoamericano. An. Antrop., n. 43, 2009, p. 9-50.

${ }^{55}$ ENCISO, ]. Design Motifs of Ancient Mexico. New York: Dover P., 1953.

${ }^{56}$ FRAUEL, Y. et. al. Detection of a polymorphic Mesoamerican symbol using a rule-based approach. Pattern Recognition, n. 39 , 2006, p. 1380-1390.
} 
símbolos mesoamericanos [...] usando uma série de regras que definem um símbolo. Uma destas regras é a presença de um único eixo simétrico [...] outras regras são referentes à sua morfologia". .7 $^{7}$

Os autores ainda ressaltam como essencial considerar a ideia de que a maioria das populações mesoamericanas se utilizou de formas plásticas para representar conceitos ligados a uma cosmovisão que não se restringe a uma sociedade em particular. "Estas imagens são portanto fontes diretas de dados sobre esse assunto [...] muito poucos estudos [...] conceberam a iconografia mesoamericana como um todo, focando nos elementos comuns encontrados em diferentes culturas, em diferentes épocas e regiões" ${ }^{58}$ Frauel et al. ainda comentam sobre a reincidência de tais imagens abstratas em templos e monumentos principais, além dos modos como estas são representadas (geralmente destacadas de outras imagens no campo pictórico), o que levou os autores a identificá-las como "símbolos".

Já Enciso denomina seu trabalho de "Motivos de Design do México Antigo", e baseia suas análises nas imagens presentes nos antigos carimbos em cerâmica, produzidos por diversas sociedades mesoamericanas. Foi notada pelo autor "uma gama imensa de motivos [...] e a extensão de sua proveniência geográfica". ${ }^{99}$ Com uma visão que buscava identificar símbolos em comum para toda a Mesoamérica, Enciso separa os motivos que identificou em "grupos temáticos", e não por localidade ou época, como procura deixar claro. ${ }^{60}$ Destaca-se que Enciso ${ }^{61}$ e Marcus $^{62}$ afirmam que carimbos eram amplamente encontrados na Mesoamérica desde o Período Formativo, e eram utilizados para decorar tecidos, corpos humanos, papel, peles de animais e cerâmica.

Por meio do estudo destes trabalhos, principalmente do grande levantamento intensivo e extensivo realizado por Enciso, percebeu-se uma quantidade considerável de símbolos em comum com os encontrados no Sudoeste. A fim de refinar ainda mais esta pesquisa, aliado aos resultados já publicados, como comentado foi também analisada a coleção mesoamericana de alguns museus. Foi dada preferência os artefatos relativos ao período Epiclássico e principalmente Pós-Clássico como um todo. ${ }^{63}$ Quanto à localização aproximada, ou quanto ao grupo humano que teria produzido estas peças, foi dada ênfase aos artefatos cuja proveniência era classificada como de áreas do Oeste do México e do Planal to Central Mexicano. ${ }^{64} \mathrm{~A}$ escolha teve como base o conhecimento prévio de rotas de comércio, e de

\footnotetext{
57 Ibidem, p. 1380

${ }^{58} \mathrm{lbid}$.

${ }^{59}$ ENCISO. op. cit., p. 5

${ }^{60}$ Seus "grupos temáticos" incluíam: formas geométricas, naturais (flora e fauna); formas associadas ao corpo humano e "formas artificiais".

${ }^{61}$ Ibid., p. 5.

${ }^{62}$ MARCUS, ]. The Origins of Mesoamerican Writing. Annual Review of Anthropology, v. 5, 1976, p. 42 (a).

${ }^{63}$ Concomitantes com o desenvolvimento dos padrões arqueológicos do Sudoeste aqui analisados.

${ }^{64}$ Mathiowetz afirma que é possível atestar que existe de fato muitas similaridades entre os motivos simbólicos encontrados no Oeste do México, com os então contemporâneos e antecedentes motivos simbólicos do Planalto Central Mexicano. "Não
} 
evidências de contatos (e/ou possíveis influências) entre estas áreas e o Sudoeste de modo geral ${ }^{65}$. Também foi levado em consideração, no caso da coleção mesoamericana do $\mathrm{AMNH}$, o fato de que esta foi formada por Carl Lumholtz, que coletou os artefatos, em fins do século XIX, percorrendo quase $1.500 \mathrm{~km}$ ao longo da Sierra Madre Ocidental, desde a fronteira do Arizona à Gualaraja, e à região Tarasca de Michoacán - uma das conhecidas rotas de comércio entre o Sudoeste e a Mesoamérica.

A presença de formas abstratas semelhantes na iconografia destas duas grandes "áreas culturais" é um fator de grande relevância. Muitas destas formas são escolhidas para compor imagens em vasos cerâmicos, também de modo semelhante ao que ocorre no Sudoeste. ${ }^{66}$ Foi notado que a organização destas formas no espaço pictórico por vezes se dá de maneira bastante similar. Pode-se dizer que foi encontrada por este estudo quase que a totalidade dos símbolos abstratos identificados nas peças da região Sudoeste também em peças da Mesoamérica. ${ }^{67}$ Nas Figuras 12 a 17 é possível observar alguns exemplos das formas gráficas similares encontradas tanto na Mesoamérica como no Sudoeste.

\section{O “código pictórico do Sudoeste" e a escrita pictoglífica mesoamericana}

É possível que na Mesoamérica, a presença das expressões consideradas como "escritas" seja tão antiga quanto a presença de alguns dos símbolos que foram identificados também no "código pictórico do Sudoeste". No caso específico da Mesoamérica, ressalta-se também a possibilidade de que alguns destes símbolos possam, devido à sua multivocalidade, serem também utilizados em "escritas", e possuírem, portanto, mais de uma "função" dependendo do contexto em que são representados.

Formas de escrita eram amplamente utilizadas pelas populações mesoamericanas, e de modo geral estas combinavam "representações pictóricas com glifos calendários, numéricos, toponímios, antroponímicos, de determinação semântica e fonéticos". ${ }^{68} \mathrm{~A}$ escrita pictoglífica pós-clássica Mixteco-

\footnotetext{
somente há similaridades formais, mas [...] também as ideias [...] e toda uma base cosmológica era também era compartilhada". MATHIOWETZ, M. The Diurnal Path of the Sun: Ideology and Interregional Interaction in Ancient Northwest Mesoamerica and the American Southwest. Tese (Doutorado em Antropologia) - Graduate Program in Anthropology, University of California Riverside, Riverside, 2011, p. 532. Focando seus estudos em Casas Grandes, Mathiowetz conclui também que conceitos simbólicos e sistemas de crença do Planalto Central Mexicano teriam influenciado não somente o Oeste do México, mas também esse padrão arqueológico do Sudoeste.

${ }^{65}$ Como por exemplo LEKSON, op. cit. e RILEY, op. cit.; entre outros.

${ }^{66}$ Tanto a maioria das peças do Sudoeste analisadas, como a maioria das da Mesoamérica, decoradas com símbolos muitas vezes em comum, eram encontradas nos mais diferentes contextos - desde esferas majoritariamente rituais até as que incluíam ações simples do dia-a-dia. Vide BARS HERING, op. cit.; NEILL, C. Intersocietal Interaction on the Northwest Mesoamerican Frontier Dissertação (Mestrado em Artes) - School of Graduate Studies, McMaster University, Hamilton, 1998

${ }^{67}$ Apenas um dos símbolos identificados para os artefatos do Sudoeste, denominado de "abertura do espírito" (uma linha circular que não se fecha, e que é geralmente identificada pelos grupos indígenas atuais como uma "abertura pela qual o espírito do vaso pode sair") não foi encontrada nos artefatos mesoamericanos analisados. BARS HERING, op. cit.

${ }^{68}$ ARCURI, M. et al. Por Ti América: Arte Pré-Colombiana. Rio de Janeiro: Pancron, 2005, p. 38-39.
} 
Nahua é interessante pois utilizava-se muito mais de glifos ideográficos do que fonéticos. "Não se relacionava [...] a uma língua específica, pois os glifos não fonéticos poderiam ter seus sentidos reabilitados por falantes de diversas línguas, desde que partilhassem as convenções do sistema" ${ }^{69}$ Neste sentido, a escrita pictoglífica deste sistema pode guardar muitas semelhanças com a estrutura do que denominamos "código pictórico do Sudoeste", embora possa também exercer outras funções, sendo capaz de produzir mensagens bem mais específicas e particulares.

Nota-se que alguns símbolos, como os relativos a formas quadripartites ou cruzes, podem tanto atuar tanto como "unidades simbólicas" que expressam ideias complexas por si só, tanto como "glifos" em um sistema de escrita. Neste último caso, os glifos são expressados graficamente de modo diferenciado e específico, de acordo com cada sistema [Figura 19]. Quando os símbolos cumprem a função de expressar, por si só, ideias complexas em uma composição, e aparecem desconectados estruturalmente de "glifos" (reconhecidamente utilizados para expressar ideias específicas, dispostas muitas vezes em formato de narrativa), eles podem não estar atuando como "glifos", mas sim como indicadores de conceitos ligados à cosmovisão, cuja complexidade não pode ser traduzida em termos ou palavras específicas. Em ambos os casos, é muito provável que os símbolos atuem como indicadores de conceitos metafísicos amplamente aceitos, como é proposto para a esfera de atuação do que é chamado aqui de "código pictórico". Como comentado, no caso mesoamericano, não pode ser negado que, devido à multivocalidade dos símbolos, estes possam cumprir a função de "glifo" e de "tradutor de conceitos metafísicos complexos" ao mesmo tempo, em uma dada composição. Deve ser lembrado que um símbolo possui diferentes níveis de significado, que podem ser apreendidos de modo diferenciado, até mesmo por membros de um mesmo grupo. É menos provável, entretanto, que em casos como os das pinturas corporais por exemplo, os símbolos cumpram também a função de indicar uma narrativa em específico, devido a sua estruturação no espaço pictórico e ao contexto de expressão gráfica. ${ }^{70}$

É importante também ressaltar que as "escritas mesoamericanas" eram em grande parte utilizadas como uma ferramenta de controle governamental, atuando por vezes como propaganda. "Apenas uma fração diminuta da sociedade mesoamericana - nobres, treinados em escolas especiais restritas à elite - aprenderam a ler".71 Diferentemente desta conjuntura, alguns do símbolos em comum com o "código pictórico" do Sudoeste, tanto na Mesoamérica como no próprio Sudoeste, poderiam ser

\footnotetext{
69 Ibidem, p. 39.

$70 \mathrm{Na}$ opinião de Thompson, "a demarcação de uma linha entre o simbolismo iconográfico e a escrita pode ser tênue - tênue o suficiente para pelo menos fazer com que os entusiastas da escrita Olmeca [...] proclamem como 'escrita' o que em outras culturas passaria como uma descrição de atributos de pintura corporal ou de tecidos”. THOMPSON apud MARCUS, op. cit. p. 35. ${ }^{71}$ MARCUS, ]. Mesoamerican Writing Systems. Propaganda, Myth and History in Four Ancient Civilizations. New Jersey: Princeton Un. Press, 1992, p.7, p. 436 (b).
} 
representados nos mais diversos locais, tendo ampla "divulgação", desde templos mesoamericanos ou murais cerimoniais entre os Pueblo, até objetos de uso "comum", como tigelas, cestos, roupas, cobertores, fusos, etc. Neste caso, não estariam cumprindo a função de passarem mensagens muito específicas, mas sim de atuarem como símbolos de ideias complexas.

Neste contexto, é válido discutir também, brevemente, o conceito de "escrita". Para a mesoamericanista Marcus, para ser considerado como escrita, um discurso teria que apresentar "uma forma e uma correspondência com a linguagem falada, o que a distingue de uma iconografia complexa". ${ }^{72}$ Também Taube e Houston acreditam que a linguagem falada não poderia ser dissociada das escritas mesoamericanas, pois haveria "evidências persuasivas de que a maior parte das escritas, independentemente de sua zona geográfica, era realizada com o intuito de ser lida em voz alta [...] a escrita era inseparável da linguagem na qual era registrada". ${ }^{73}$ ]á Johansson acredita que o caso do sistema Mixteco-Nahua ilustra uma condição diferenciada de "escrita", por não possuir necessariamente uma correlação inseparável do discurso oral. "Existia um discurso pictórico, paralelo ao discurso oral, que teria sua expressividade própria. [...] A imagem era impressa diretamente em esferas cerebrais sem que tivesse que ser processada verbalmente para ser apreendida: se pensava em imagem também" ${ }^{74}$ Também Boone e Mignolo ${ }^{75}$ já haviam questionado o conceito de "escrita" com base no conhecimento sobre o funcionamento do sistema Mixteco-Nahua. Foi ressaltada a ideia de que existem "pensamentos" que melhor seriam descritos e interpretados por meio de imagens, pois transcenderiam, em seus significados complexos, o que as palavras escritas poderiam descrever.

Como afirma Johansson, apesar da escrita do sistema Mixteco-Nahua não possuir necessariamente correlação no discurso oral, ela tem a capacidade de descrever "feitos e acontecimentos". O mesmo afirmam Boone e Mignolo, quando dizem que o texto Mixteco-Nahua relata "ideias relativamente específicas". A esfera de atuação do "código pictórico" aqui proposto, não corresponderia a princípio, a formas de expressão que descrevem eventos específicos, ou nomenclaturas. Seus símbolos atuariam, primordialmente, como "traduções" de uma cosmografia. E isso ocorre tanto nas populações mesoamericanas (que possuem, a princípio: "escrita"; símbolos que podem estar atuando também em

\footnotetext{
72 Ibidem, p. 17

73 TAUBE, K.; HOUSTON, S. An Archaeology of the Senses: Perception and Cultural Expression in Ancient Mesoamerica. Cambridge Archaeological Journal, v. 10, 2000, p. 263

${ }^{74}$ JOHANSSON, P. K. Mitología, Mitografía y Mitokinesia. Una Secuencia Narrativa de la Peregrinación de los Aztecas. Estudios de Cultura Náhuatl, n. 39, 2008, p. 17.

${ }^{75}$ BOONE, E.H.; MICNOLO, W. D. Writing without words: Alternative Literacies in Mesoamerica and the Andes. Londres: Duke University Press, 1994.
} 
"códigos pictóricos" próprios; e arte naturalista), tanto quanto no Sudoeste (cujas populações, a princípio expressam em sua iconografia um “código pictórico" e formas naturalistas de expressão plástica).

A discussão do conceito de "escrita" pode tornar-se bastante complexa. Caso seja levado em consideração o fato de que "escrita" possa extrapolar esta questão da especificidade do discurso, seria possível considerar também que, o que aqui está sendo denominado de "código pictórico", pudesse ser enquadrado nesta categoria. Johansson utiliza o termo "mitografia" para referir-se ao sistema MixtecoNahua de escrita.

Neste caso, a imagem alimenta o espírito do leitor sem que este tenha uma consciência verbal dela (...) Este fato é importante já que determina uma modalidade pré-colombiana de apreensão do mundo mediante uma estruturação pictórica da cognição que permite ao indígena pensar em imagens e transmitir pictoricamente as impressões mais profundas e sutis que compõe sua sabedoria ancestral. ${ }^{76}$

Portanto, se levada em conta esta concepção, a apreensão de conceitos da cosmovisão amplamente compartilhados, expressos pelos símbolos que compõe o que aqui foi denominado de "código pictórico", poderia também se encaixar neste conceito mais amplo de "escrita".

Johansson também se preocupa, de qualquer modo, em distinguir o que seria, em suas palavras, um "elemento pictórico" que estaria ligado a uma configuração de sentido (como uma narrativa), de outro que atuaria como um indicador de uma ideia complexa por si só. "Em muitos casos estas distinções não podem ser resolvidas no nível do signo, apenas no momento de sua integração ao sistema. É este sistema como unidade semiológica que determina sua pertinência específica de um signo". ${ }^{77}$ Como comentado, um dado símbolo pode, de fato, cumprir a função de "glifo" e de "símbolo tradutor de conceitos metafísicos complexos" ao mesmo tempo. Como aponta também Johansson ${ }^{78}$, existem vários níveis de leitura, assim como existem vários possíveis significados que podem ser expressos pelo mesmo símbolo.

Apesar da articulação dos símbolos que compõe o que aqui é considerado como "código pictórico do Sudoeste" ser comparável a uma articulação gramatical, ela não expressaria, a princípio, ideias e relatos específicos - como as ditas "escritas mesoamericanas" são capazes de expressar. A arqueologia não possui ainda neste momento uma metodologia (ou dados suficientes) que permita afirmar que, além destes símbolos atuarem como elementos de um código pictórico "tradutor da cosmovisão vigente", eles também pudessem ser combinados para indicar acontecimentos particulares, e serem lidos desta forma por certas comunidades (que talvez pudessem compartilhar de um código de combinações de elementos

\footnotetext{
${ }^{76}$ JOHANSON, op. cit., p. 31.

77 Ibidem.

${ }^{78}$ Ibidem, p. 35-36.
} 
gráficos que funcionasse tal como o sistema Mixteco-Nahua). Ou seja: não há como indicar, considerando-se a grande maior parte das expressões gráficas do Sudoeste, que além de atuarem na expressão de conceitos atemporais, estes símbolos também atuassem como narrativas específicas de fatos ocorridos no que se compreende como "tempo linear", ou mesmo em um "tempo mítico" que contasse um fato em particular.

Existem algumas exceções, entretanto, no caso dos Pueblo, apesar de raras. Estas podem constituir talvez exemplos de uma "escrita" que lembre um pouco a estruturação utilizada pelo sistema Mixteco-Nahua. Alguns estudiosos acreditam que possa existir, dentre os Pueblo atuais, símbolos que possam funcionar como "glifos", e que estes possam indicar algumas "leituras" mais específicas em contextos arqueológicos ${ }^{79}$. Dentre os Hopi (falantes de língua uto-asteca), o símbolo composto por quatro linhas desenhado sobre qualquer passagem ${ }^{80}$, dentro ou fora de uma estrutura, transmite a mensagem que esta passagem está "fechada" para intrusos. Também Schaafsma ${ }^{81}$ aponta a existência de certos contextos pictóricos Hopi específicos, nos quais pinturas rupestres foram interpretadas pelos próprios Hopi como narrativas de eventos. Nesses contextos, certas imagens de círculos podem ser compreendidas como símbolos de força, proteção ou "escudos". Estes símbolos podem tanto representar força e proteção para quem os desenha, como ocasionalmente pode também indicar os escudos inimigos vencidos, representando o poder de uma luta bem sucedida. Quando isso ocorre, estes "escudos" são representados ao lado de símbolos de contagem, indicando o número de mortes em batalha. "Neste caso particular de exemplo histórico, os escudos entretanto são os de inimigos, não são os dos Hopi. E os símbolos de amizade e o símbolo da lua no escudo estariam relacionados ao evento, sem implicações mágicas" ${ }^{82}$ Apesar da interpretação Hopi ser a de um evento em específico, não se acredita aqui, de qualquer modo, que o que a autora denomina de "implicações mágicas" esteja dissociado destas imagens rupestres, reconhecidamente "dotadas de poder" para os habitantes do Sudoeste em geral, levando-se também em consideração a multivocalidade dos símbolos.

Tais exemplos, entretanto, são raros no contexto do Sudoeste antigo, e possuem em geral uma estruturação pictórica mais específica. Há de qualquer modo também a atribuição de certos significados mais específicos aos símbolos dentre os Pueblo atuais, mas estas, de modo geral, não correspondem a narrativas ou informam acontecimentos em detalhe. Símbolos deste código podem ser "lidos" pelos Pueblo, por exemplo, também como indicadores de metáforas para "chuva", "colheita", "voo do pássaro

\footnotetext{
${ }^{79}$ ELLIS, F.; HAMMOCK, L. The Inner Sanctum of Feather cave: A Mogollon Sun and Earth Shine Linking Mexico and the Southwest. American Antiquity, v. 33, n. 1, 1968, p. 25-44

${ }^{80}$ Aqui neste estudo considerado como um dos símbolos do "código pictórico do Sudoeste".

${ }^{81}$ SCHAAFSMA, P. Warrior, Shield, and Star: Imagery and Ideology of Pueblo Warfare. Santa Fe: Western Edge Press, 2000.

${ }^{82}$ Ibidem, p. 111
} 
trovão", "nuvens nas montanhas", etc. Complementando estas colocações, deve também ser lembrado que, mesmo considerando-se certos graus de especificidade nestes possíveis "glifos" Hopi, Parsons ${ }^{83}$ comenta que "ao ganhar meu 'nome' Hopi, meu 'pai', para explicar-me seu significado, desenhou um glifo de nuvem de chuva, familiar a todos os Pueblo. Se os Hopi quisessem fazer registros históricos de pessoas, ou de períodos, ou de tributos, eles teriam desenvolvido algo mais parecido com os glifos astecas".

\section{Apontamentos Finais}

Pode-se dizer que o que aqui denominou-se "código pictórico", é algo para ser lido, mas que não pode ser reduzido a uma linguagem escrita. Algo para ser visto, mas que não pode ser reduzido à contemplação. Algo que era compartilhado por sociedades que falavam diferentes línguas, e habitavam terras por vezes muito distantes.

O "código pictórico do Sudoeste" é composto por um conjunto de sememas finitos, que poderiam ser combinados de diversas maneiras. A continuidade da expressão não só de sememas em comum, mas também de sintagmas e sintaxes específicas ao longo do tempo, demonstra que não somente as ideias expressas pelos sememas principais pudessem ter sido compartilhadas, mas também combinações específicas dessas ideias. Sua permanência em peças etnográficas denota a presença de um fator de coesão, que permitiu que tais símbolos não deixassem de ser representados, mesmo em meio a um contexto que provocou tantas mudanças significativas em diversos graus e âmbitos das sociedades Pueblo. Por fim, destaca-se que muitos desses símbolos estão também presentes na iconografia da região mesoamericana, expondo a existência de uma rede de interação simbólica entre essas duas grandes regiões.

${ }^{83}$ PARSONS, E. C. Pueblo Indian Religion. Chicago: University of Chicago Press, 1939, v. II, p. 1023. 


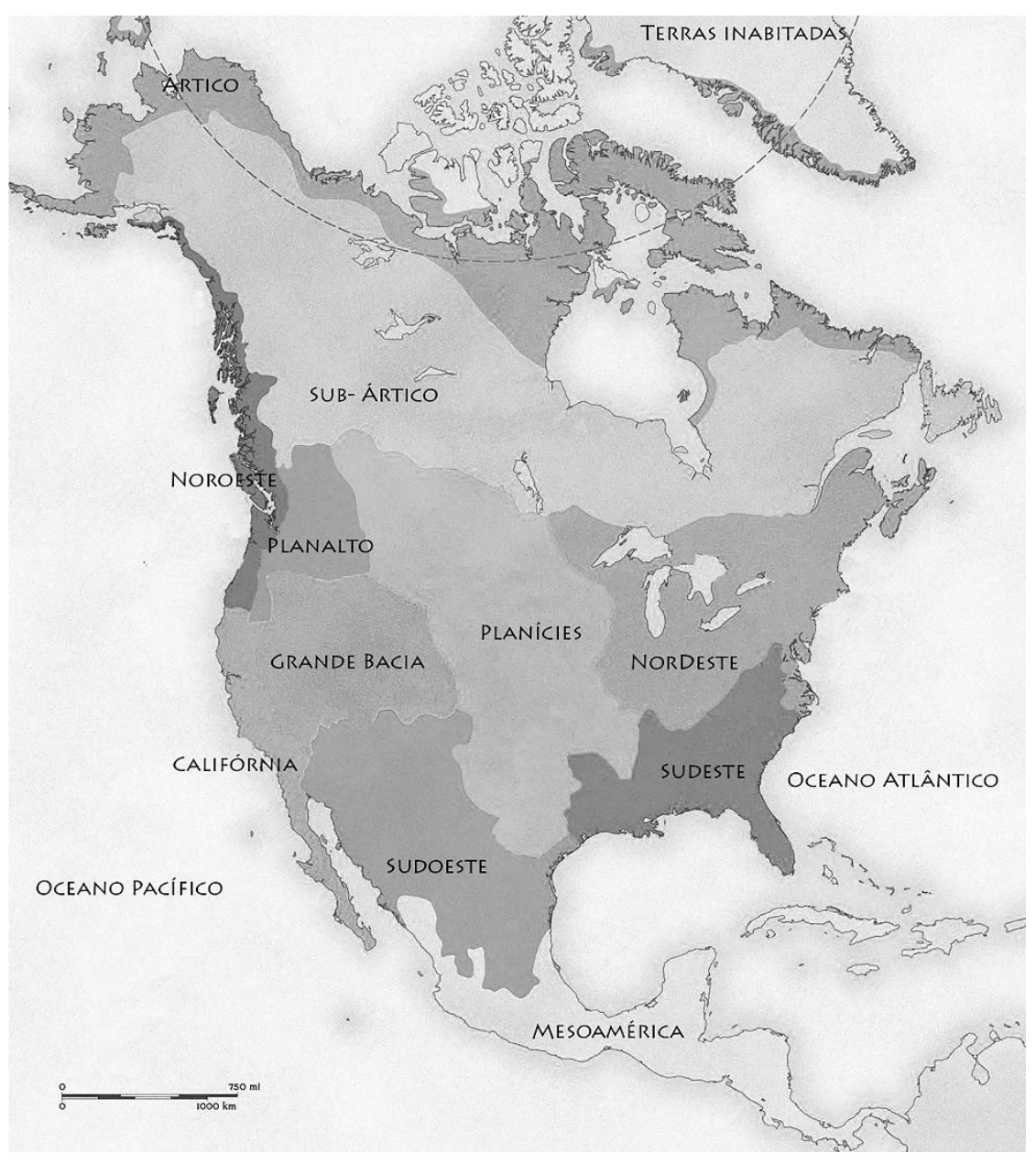

Figura 1:

Mapa com as subdivisões em "áreas culturais" da América do Norte, incluindo a Região Sudoeste e a Mesoamérica. ${ }^{84}$

Figura 2:

Mapa com a localização aproximada na paisagem dos assentamentos das sociedades pertencentes aos padrões arqueológicos assumidos para o Sudoeste aqui em estudo. O padrão Casas Grandes localiza-se aproximadamente no local onde foi inserida sua denominação, sendo uma expressão tardia. Concepção artística da autora.

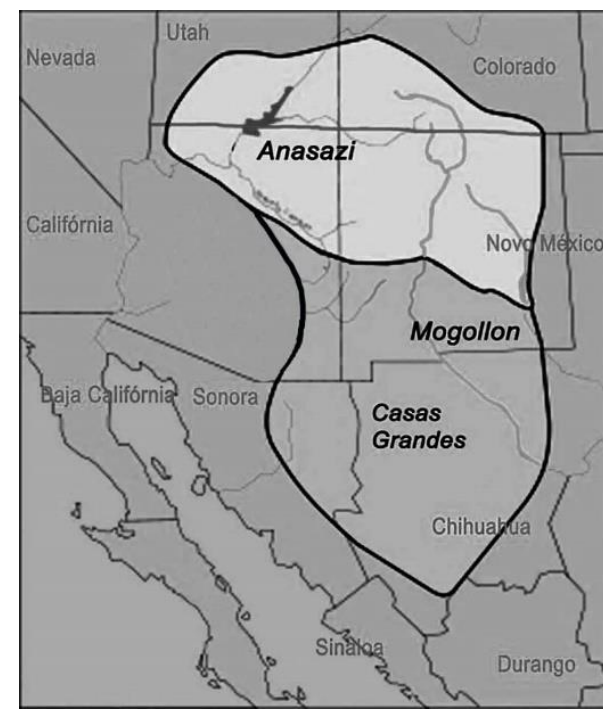

${ }^{84}$ Mapa modificado e traduzido pela autora, com base em mapa divulgado pela Maine Farmington University (2011). Disponível em: http://faculty.umf.maine.edu/walter.sargent/public.mww/web\%20230/unit\%201\%20old\%20worlds.html. Acesso em: 26 abr. 2011. 
Figura 3:

Vaso Cerâmico. Sítio de Fourmile Ruin

- Pueblo IV (Anasazi/ Pueblo Antigo)

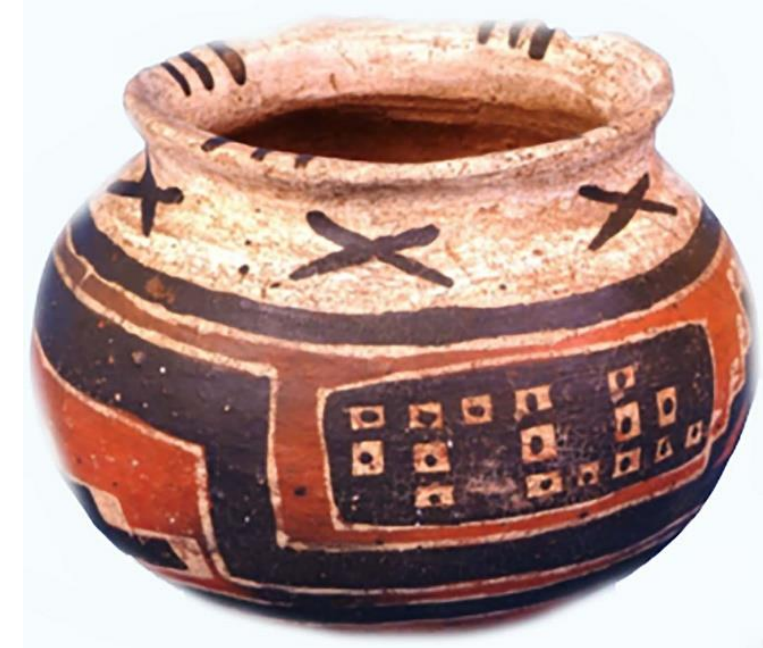

Acervo do NMNH.

Figura 4:

O semema do escalonado: exemplos de

diferentes estilos de representação.

Ilustrações da autora, a partir de peças analisadas da coleção do NMNH.
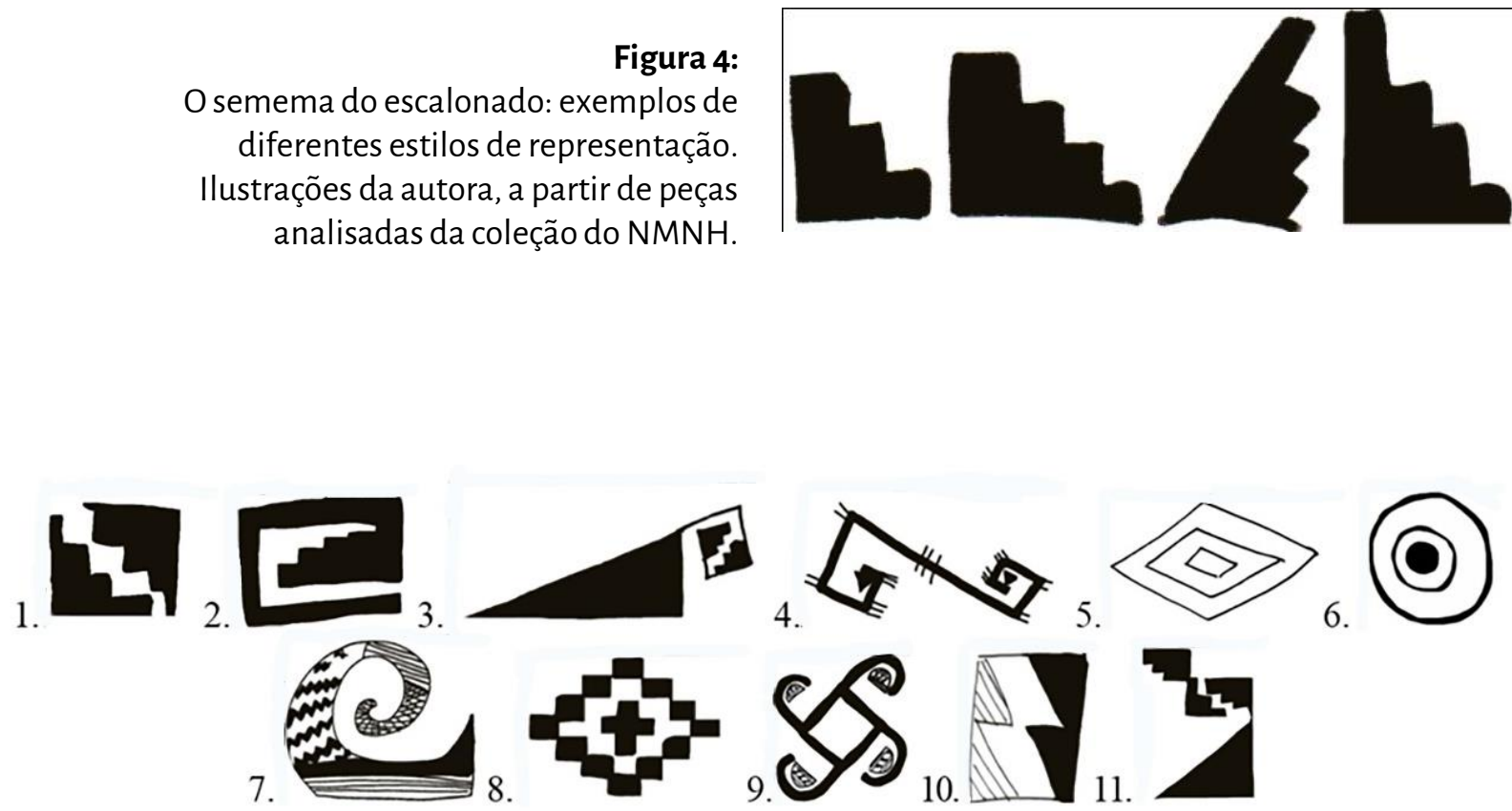

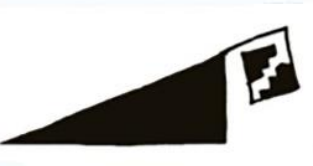

4.

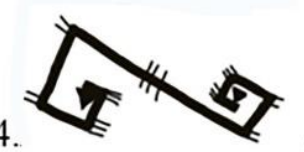

5 .

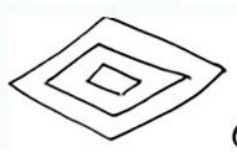

6.
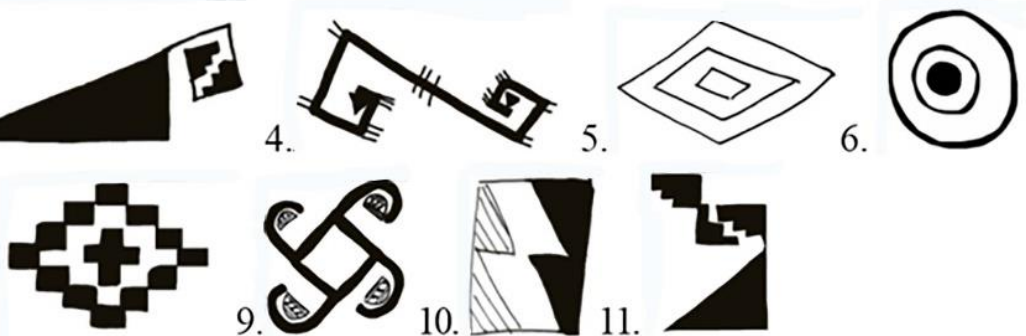
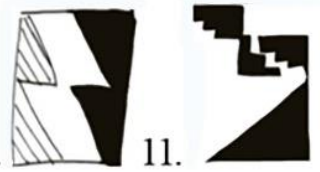

\section{Figura 5:}

Exemplos de diferentes símbolos, compostos pela combinação de diferentes sememas. 1: sintagma composto por escalonados espelhados; 2 : sintagma composto por escalonado e voluta; 3 : composto por triângulo, escalonados e voluta; 4: combinação de volutas, triângulos e linhas; 5 : diamantes concêntricos; 6 : círculos concêntricos; 7: voluta com preenchimento de linhas paralelas e zigue-zagues; 8 e 9: símbolos quadripartites; 10: Sintagma formado por triângulos em sequência espelhados e 11: sintagma composto por escalonados e triângulos.

Ilustrações da autora a partir de peças do acervo do LMA e NMNH. 


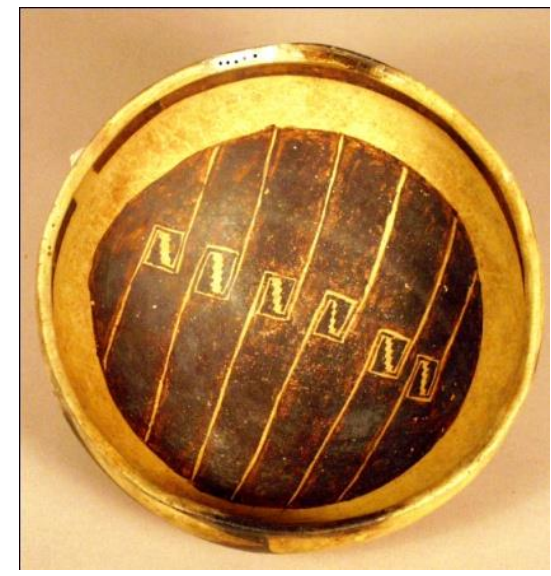

Figura 6:

Tigela Pueblo IV - Hopi HomolobiJeddito Yellow ware (Anazasi/ Pueblo Antigo).

Coleção NMNH e LMA

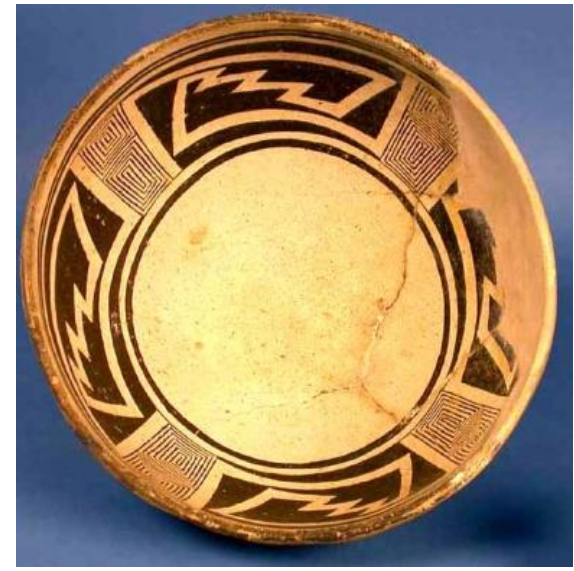

Figura 7:

Tigela Mimbres Mogollon. Coleção NMNH e LMA

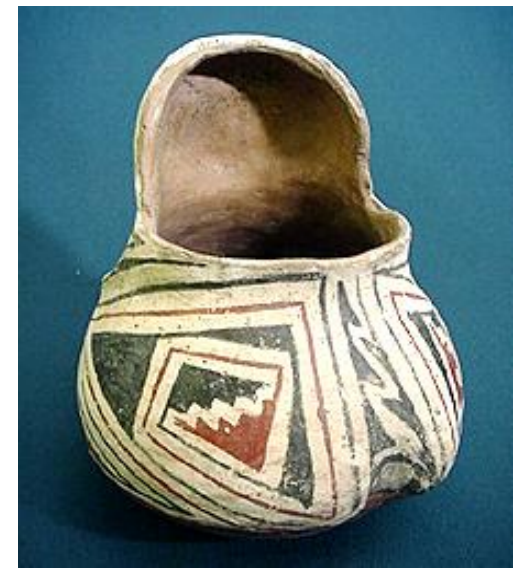

Figura 8:

Parte posterior de vaso escultórico Casas GrandesChihuahua Red Ware - Villa Ahumada Polychrome. Coleção NMNH e LMA

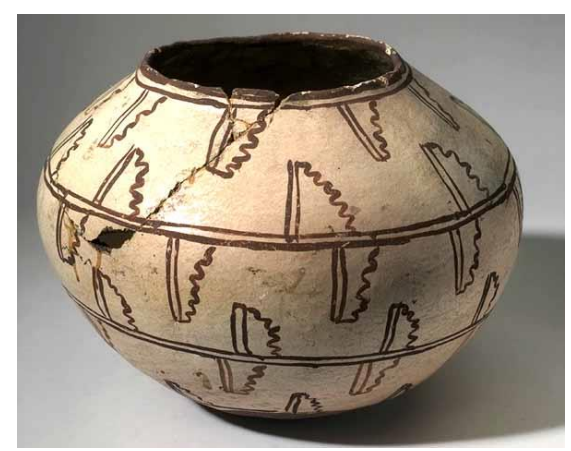

Figura 9:

Artefato etnográfico Pueblo Zuni: vaso cerâmico com representações de sememas de "escalonados". Coleção AMNH.

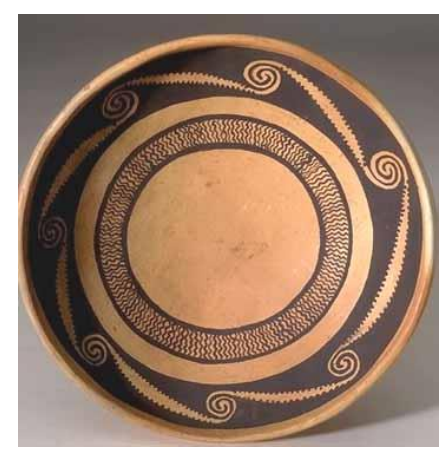

\section{Figura 10:}

Artefato etnográfico Pueblo Hopi: tigela com representações de sintagmas de "triângulos com voluta na ponta ziguezagueados"). Coleção AMNH.

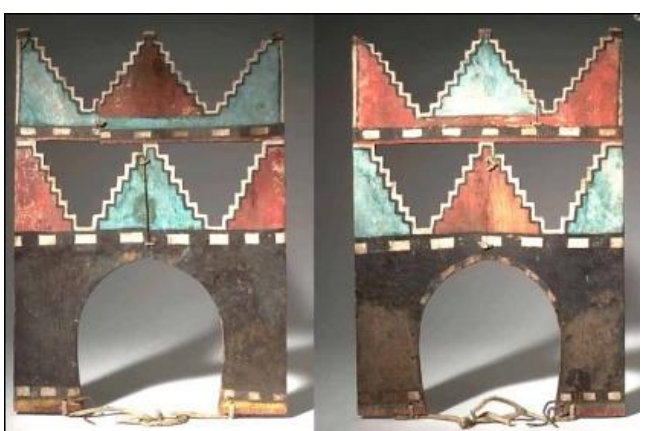

Figura 11:

Artefato etnográfico Pueblo Hopi: ornamento de dança ritual (toucado) em madeira, com representações de sintagma de "escalonado tipo pirâmide". Coleção AMNH. 

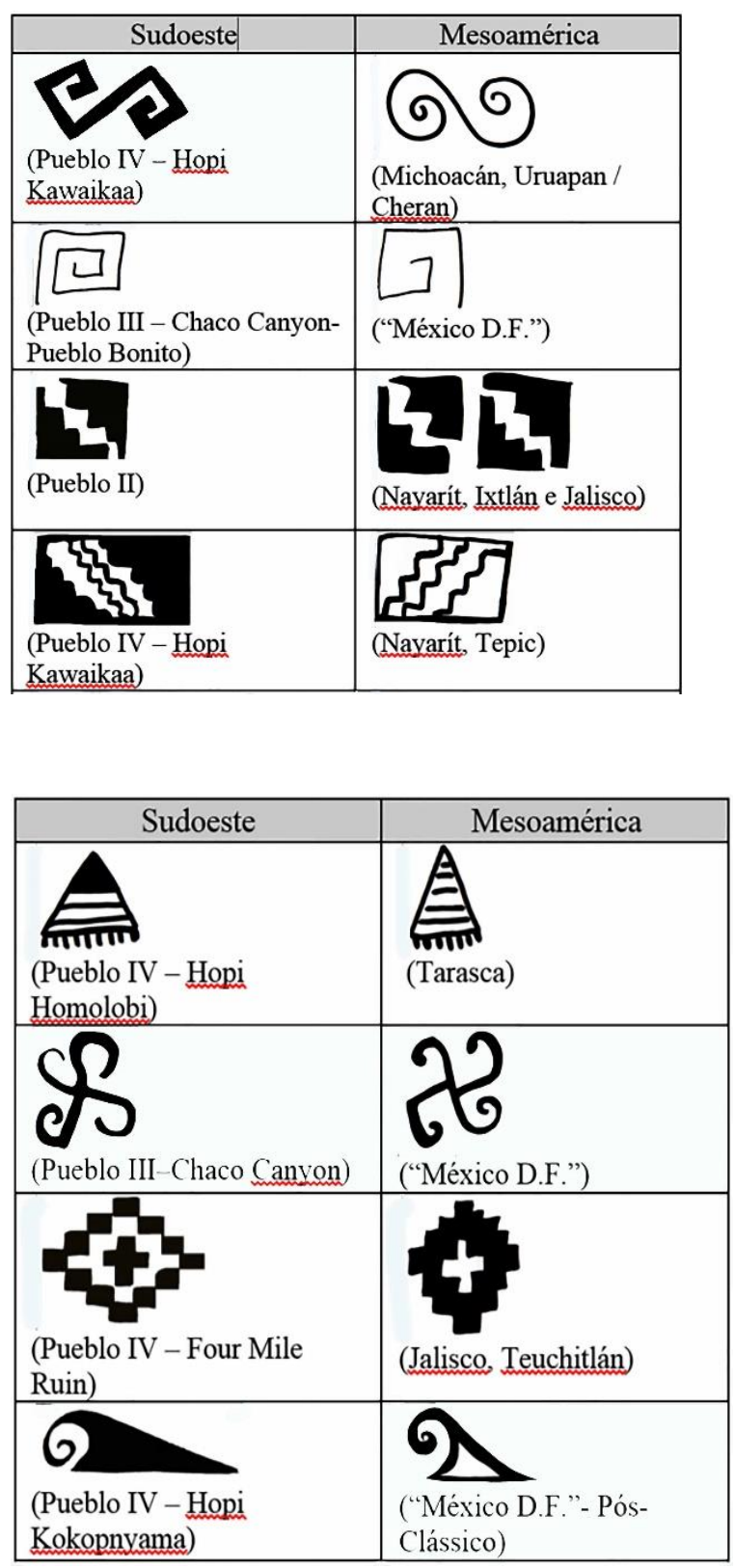

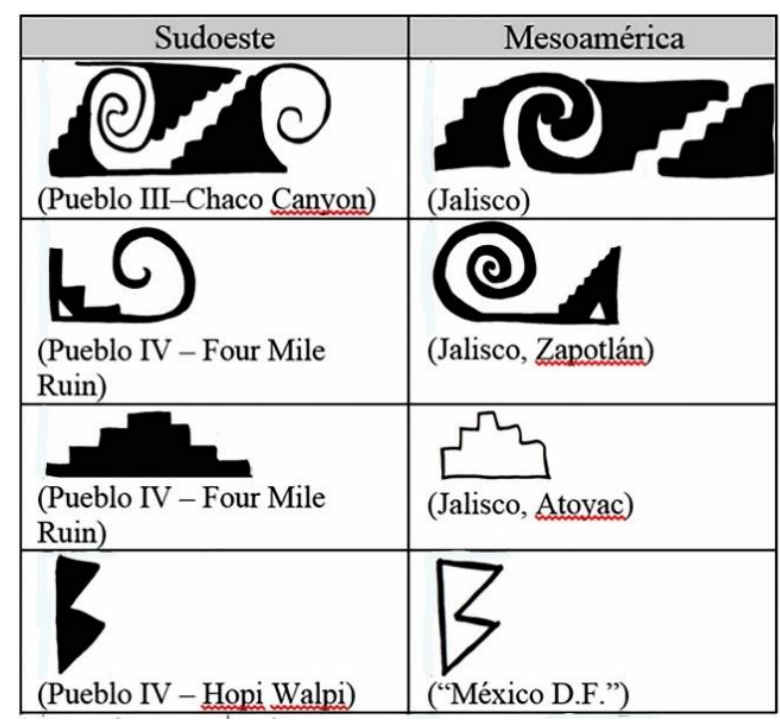

\begin{tabular}{|l|l|}
\hline \multicolumn{2}{|c|}{ Sudoeste } \\
\hline (Pueblo IV-Hopi Walpi)
\end{tabular}

\section{Figuras 12, 13, 14 e 15:}

Quadros comparativos demonstrando as similaridades entre símbolos encontrados representados na iconografia dos padrões arqueológicos da Região Sudoeste e da Mesoamérica.

Ilustrações da autora a partir peças do acervo do NMNH e AMNH. 

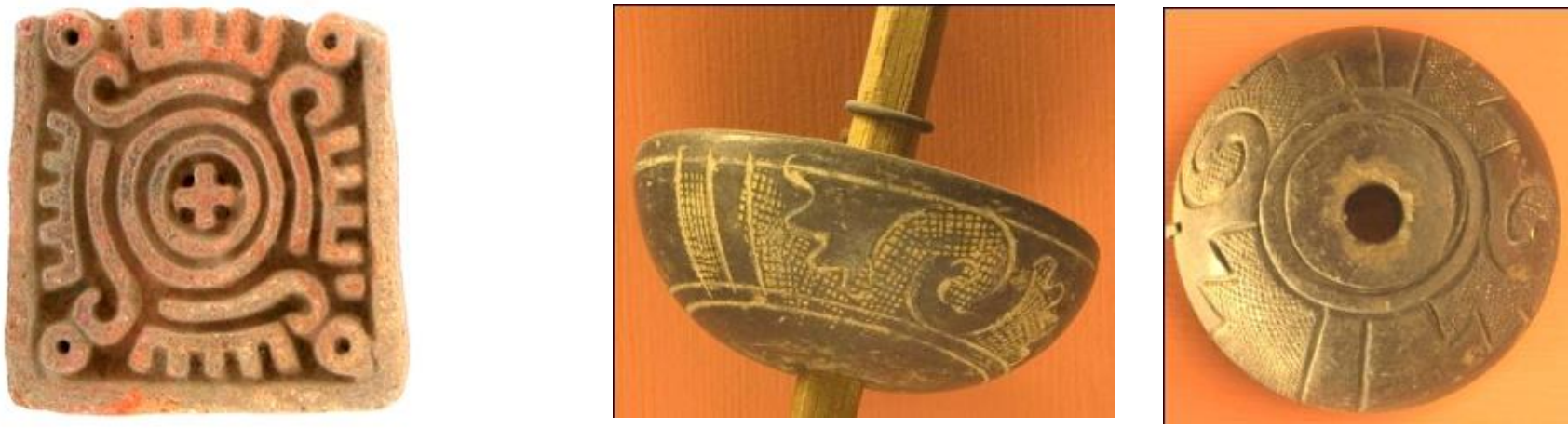

Figuras 17 e 18:

Figura 16:

Carimbo mesoamericano com símbolo quadripartite. A procedência exata é desconhecida, sendo descrita apenas como "México". Coleção do NMNH.
Fusos datados do período Pós-Clássico, classificados como "astecas" (Mexica). Apresentam sintagmas formados por escalonados e volutas. Coleção do AMNH.

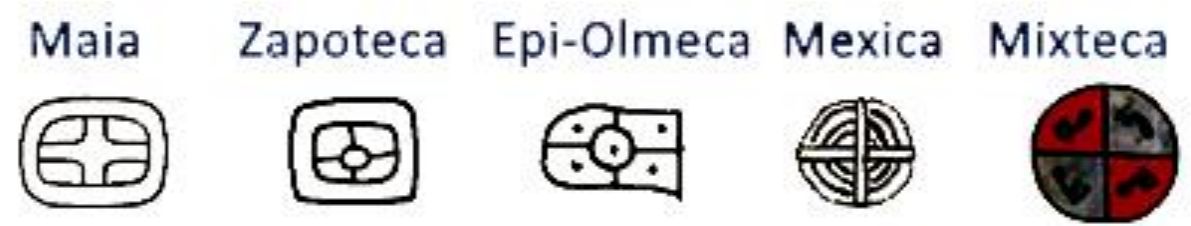

Figuras 19:

${ }^{85}$ Imagem construída a partir de LO, Lawrence. Mesoamerican Writing Systems. In: Ancient Scripts. Disponível em: http://www.ancientscripts.com/ma_ws.html. Acesso em: 27 out. 2011. 